\title{
IMPACT OF ILLNESS PERCEPTION AND COPING STRATEGIES ON QUALITY OF LIFE AMONG MIGRAINEURS
}

\author{
Humaira Bibi, Summaira Naz, Mussarat Jabeen Khan* \\ Hazara University, Mansehra Pakistan, *International Islamic University, Islamabad Pakistan
}

\begin{abstract}
Objectives: To find out the impact of illness perception and coping strategies on quality of life among migraineurs.

Study Design: Correlational study.

Place and Duration of Study: The sample was selected from different hospitals of Hazara Division, from Mar to Jul 2018.

Methodology: The sample of 300 migraineurs with age range 18-55 years was selected from hospitals of Hazara Division through purposive sampling technique. Brief illness perception questionnaire, The World Health Organization Quality of Life Scale (WHOQOL-BREF) and brief cope scale were used for data collection.

Results: Illness perception significantly predicted $(p=0.002)$ quality of life in positive direction. The results also explored that positive coping $(p \leq 0.001)$ and problem focused coping strategies $(p=0.002)$ predict quality of life significantly positively; whereas active avoidance coping strategies $(p \leq 0.001)$ significantly negative predict quality of life; while religious denial coping was non-significant predictor of quality of life.

Conclusion: Illness perception has significant negative relationship with quality of life, problem-focus coping (PFC), and positive coping (PC). Illness perception has significant positive relationship with religious denial coping (RDC) and active avoidance coping (AAC).
\end{abstract}

Keywords: Coping strategies, Illness perception, Migraine, Quality of life.

This is an Open Access article distributed under the terms of the Creative Commons Attribution License (https://creativecommons.org/licenses/by-nc/4.0/), which permits unrestricted use, distribution, and reproduction in any medium, provided the original work is properly cited.

\section{INTRODUCTION}

Migraine is a severe type of headache that effects one side of the head. It is more common in females as compared to males with 3:1. Migraine headache is a disabling disease that has aversive effects on occupational, family and social life of migraineurs, so the quality of life of these patients is very low ${ }^{1}$.

Illness perception is related to specific cognitive representations that are related to health quality of patients. It plays major role in psychological wellbeing of individuals. It is the set of beliefs made by patients about their health problems. These beliefs affect the selection of their coping strategies to deal with their mental or physical illness ${ }^{2}$.

Recovery from illness depends on how patients perceive their illness and how they cope with their disease. So the perception of illness depends on how people respond to their illness. Illness perception is based on five cognitive constituents, these are: reasons of illness, identity, consequences of illness, time line and methods to control or cure the illness ${ }^{3}$.

Quality of life is a study of a persons' capacity to operate or to perform physically, socially and emotionally withintheir environment at a level which is con-

Correspondence: Dr Mussarat Jabeen Khan, Asst Prof, Department of Psychology, International Islamic University Islamabad Pakistan Received: 28 Jan 2020; revised received: 21 Sep 2020; accepted: 01 Oct 2020 sistent with their own predictions. It is multidimensional concept and it can be categorized in a) material wellbeing b), physical wellbeing, c) emotional and social wellbeing, d) activity and development ${ }^{4}$. Health related quality of life is low among migraine patients as compared to non migraineurs. A study concluded that migraine has aversive effects on quality of life ${ }^{5}$.

Coping refers to the perceptions, concepts and operations that people use to deal with stress. Coping strategies are the purposeful efforts persons' engage in to lessen the psychological, social or physical harm of any situation or event ${ }^{6}$.

According to Lafittau et $a l^{6}$, migraine patients have reported severely impaired quality of life. Similarly, to use dysfunctional coping techniques against pain also causes bad emotional adjustment in those patients. Quality of life is affected by an individual's coping abilities in a causal direction. The duration and frequency of migraine headache both have major effects on quality of life of children. Migraineurs report compromised mental, social and physical functioning, especially those who have a high occurrence of migraine attacks 7,8 .

The objectives of the present study were to measure inter-relationship among illness perception, coping strategies and quality of life; and to measure the impact of illness perception and coping strategies on quality of life among migraine patients. 


\section{METHODOLOGY}

Correlational research design was used in the present study. The study was conducted in March 2018 to July 2018. The sample was selected from the hospitals of Abbottabad, Mansehra, Havelian, and Haripur by using purposive sampling technique. Migraine is a common neurological disorder, prevalent up to $6 \%$ in men and $18 \%$ in females with the highest prevalence age from 20-55 years. Sample size was calculated by using the WHO sample size calculator, considering $5 \%$ margin of error and $95 \%$ confidence interval ${ }^{9}$. The sample for the present study comprised 300 diagnosed migraine patients (men, $\mathrm{n}=150$, and women, $\mathrm{n}=150$ ) with age ranging from $18-55$ years. These patients were contacted after taking permission from department of Psychology IIUI Ethics Committee (31DPEC). Only diagnosed migraine patients were included in this sample and patients with any other psychiatric disability were excluded.

The brief illness perception questionnaire has eight items and an additional item, which investigates the causal factors. First eight items on the scale had a Likert- type scoring between $0-10$. Item 9 is an openended question that requires an open-ended response, it provides information about the most significant causal factors of their illness (scores on the scale shows how threatening the illness is or how relaxed the person is regarding the illness. Items 3, 4, and 7 are reversed scoring items. A higher score reflects that a person feels more threatened by the illness ${ }^{10}$.

The WHO Quality of Life-BREF is a short form of WHOQOL-100, it comprises 26 items. The English version of WHO-QOL BREF was translated in Urdu ${ }^{11}$. It has 26 items. Scoring criteria is five point likert scale, from $1=$ strongly disagree to $5=$ strongly agree. The highscores indicated high level of quality of life and vice versa.

Brief cope scale initially developed and Urdu translation was done ${ }^{12}$. It has 28 items. This scale has 4 subscales; problem focused coping, positive coping, religious denial coping and active avoidance coping. Scoring criteria is 4 point likert scale.

The sample of migraine patients was approached within the premises of Mansehra, Haripur, Abbottabad, and Havailian. Before distribution of questionnaires written inform consent was taken from the sample on informed consent form. After obtaining inform consent demographic sheet along with written questionnaires were distributed. They were instructed to complete every item of each questionnaire as honestly as possible. After data collection, Statistical Package for Social Sciences (SPSS) version 20 was used to analyze the data, different statistical analysis were performed like, Reliability coefficients were computed to investigate the consistency of scales. Correlation analysis was conducted to see the relationship between study variables. Regression analysis was done to predict quality of life from illness perception and different types of coping strategies.

\section{RESULTS}

There were 150 (50\%) male migraine patients and $150(50 \%)$ female migraine patients. Mean age of male migraine patients are $42.50 \pm 1.50$ whereas mean age of female migraine patients are $47 \pm 3.75$.

The reliability value for brief illness perception questionnaire was 0.78 , for WHO quality of life scale was 0.88 , and for brief cope scale was 0.73 ., which showed that all scales have satisfactory level of reliability. Similarly the reliability value for all subscales of brief cope scale was also above average, as for positive coping alpha value was 0.61 , for problem focused coping it was 0.66 , for active avoidance coping value was 0.63 and for religious denial coping alpha value was 0.64 . Significant item total correlation of brief illness perception questionnaire, WHO-quality of life scale and brief cope scale indicated that these instruments have good construct validity.

The results of table-I showed that illness perception has significant negative correlation with quality of life, positive coping and problem focused coping strategies; and has significant positive correlation with religious denial coping strategies. Table results also showed that quality of life has significant positive correlation with problem focused coping and positive coping. It was found that active avoidance coping has significant negative correlation with problem focused coping and positive coping; and has significant positive correlation with religious denial coping. Similarly, problem focused coping was significantly positive correlated with positive coping. Table-II indicates that illness perception significantly predict the quality of life in a negative direction.

Table-III indicated that both positive coping strategy $\left(\beta=0.29^{* * *}, \mathrm{t}=4.38, p=0.000\right)$ and problem focused coping strategies $\left(\beta=0.21^{* *}, \mathrm{t}=3.17, p=0.002\right)$ predict quality of life in a significant positive way. Active avoidance coping strategy act as a significant negative predictor of quality of life $\left(\beta=-0.24^{* * *}, \mathrm{t}=-4.26, p=0.000\right)$. Similarly, religious denial coping strategy non-significantly predicted quality of life $(\beta=0.02, t=0.41, p=.686)$. 
Table-I: Correlation coefficient among illness perception, quality of life, active avoidance coping, problem focused coping, positive coping and religious denial coping $(n=300)$.

\begin{tabular}{l|c|c|c|c|c|c}
\hline Scales & $\mathbf{1}$ & $\mathbf{2}$ & $\mathbf{3}$ & $\mathbf{4}$ & $\mathbf{5}$ & $\mathbf{6}$ \\
\hline Illness Perception & - & $-0.18^{* *}$ & 0.02 & $-0.33^{* *}$ & $-0.29^{* *}$ & $0.27^{\text {** }}$ \\
\hline Quality of Life & - & - & -0.11 & $0.33^{* *}$ & $0.34^{* *}$ & -0.05 \\
\hline Active Avoidance Coping & - & - & - & $-.21^{* *}$ & $-.28^{* *}$ & $.18^{* *}$ \\
\hline Problem Focused Coping & - & - & - & - & $0.59^{* *}$ & -0.03 \\
\hline Positive Coping & - & - & - & - & - & -0.09 \\
\hline Religious Denial Coping & - & - & - & - & - & - \\
\hline Mean & 38.15 & 81.61 & 24.79 & 19.81 & 18.55 & 11.76 \\
\hline Standard Deviation & 10.48 & 14.17 & 4.08 & 3.64 & 3.29 & 2.61 \\
\hline ***< & & & &
\end{tabular}

${ }^{* *} p<0.01$.

Table-II: Linear regression predicting quality of life from illness perception $(n=300)$.

\begin{tabular}{l|c|c|c|c|c|c|c}
\hline Predictor & R & R2 & B & B & SE & F & p-value \\
\hline Illness perception & 0.18 & 0.03 & -0.24 & $-0.18^{\star *}$ & 0.08 & $9.68^{* *}$ & 0.002 \\
\hline
\end{tabular}

Table-III: Multiple regression analysis predicting quality of life from coping strategies $(n=300)$.

\begin{tabular}{|c|c|c|c|}
\hline Predictor & B & B & p-value \\
\hline Positive coping & 1.25 & $0.29 * * *$ & $<0.001$ \\
\hline Problem focused coping & 0.79 & $0.21^{* *}$ & 0.002 \\
\hline Active avoidance coping & -0.83 & $-0.24^{* * *}$ & $<0.001$ \\
\hline Religious denial coping & 0.12 & 0.02 & 0.686 \\
\hline $\mathrm{R} 2$ & & 0.19 & \\
\hline $\mathrm{F}$ & & $17.53^{* * *}$ & \\
\hline
\end{tabular}

\section{DISCUSSION}

The results of present research revealed that illness perception has significant negative relationship with quality of life and two types of coping (PFC and PC). Asnani et al ${ }^{13}$ also supported the findings of the current research and stated that illness perception is negatively associated with quality of life problem focus coping and positive coping ${ }^{14}$. Holubova et al ${ }^{15}$ studied the quality of life of patients were mainly focused on demographic variables, intensity of symptoms, and medical intervention; Zang et al ${ }^{16}$ carried out a research to explore the impact of psychological factors including illness perception and its effect on quality of life of the patients.

The present research revealed that illness perception has significant positive relationship with RDC and AAC. These findings are supported by one previous research, which revealed negative relationship among illness perception, religious denial, and active avoidance coping. Quality of life was found to be negatively associated with negative coping (religious denial and active avoidance) and positively associated with positive coping strategies (problem focused coping and positive coping). A previous study by Vazquez-Colon et al ${ }^{17}$ also confirmed the results of the present research by exploring that quality of life is higher in people using positive coping strategies and lower in those who use negative coping strategies.

The current study revealed that illness perception and religious denial coping strategy significantly predicted quality of life in negative direction. Tiemensma et al ${ }^{18}$ provided support to these findings by concluding that illness perception predicts quality of life negatively. Broadbent et al ${ }^{19}$ concluded that both illness perception and coping strategies are important predictors of quality of life. The more threatening a patient feels about his illness, the more he will use avoidant and denial coping, the poorer the quality of life will be and negative coping strategies (avoidant and denial coping) negatively predict quality of life. Dempster et al ${ }^{20}$ revealed that both PFC and PC positively predict quality of life.

The present research was confronted with some limitations. It was conducted only on migraine patients of Hazara Division. So it is suggested for the future research that other areas of KPK and Pakistan should also be included. In the current study the demographic differences on these variables were not explored, due to time restraint. So it is suggested that in future studies demographic variables should also be included.

The current study will be helpful in both theoretical and practical fields; findings of the study will contribute in literature by adding new information. These findings are beneficial for migraine patients to know about their characteristics, and by giving information that with the help of positive coping strategies they can improve their quality of life, the less they perceive their illness as threatening the more they will involve in positive coping strategies, the better will be their quality of life. 


\section{CONFLICT OF INTEREST}

This study has no conflict of interest to be declared by any authors.

\section{REFERENCES}

1. Shaik MM, Hassan MB, Tan HL, Gan SH. Quality of life and migraine disability among female migraine patients in a tertiary hospital in Malaysia. Biomed Res Int 2015; 523717(2b): 1-9.

2. Cavelti M, Contin G, Beck EM, Kvrqic S, Kossowsky J, Stieglitz $\mathrm{RD}$, et al. Validation of the illness perception questionnaire for schizophrenia in a German-speaking sample of outpatients with chronic schizophrenia. Psychopathol 2012; 45(4): 259-69.

3. Princip M, Gattlen C, Meister-Langraf RE, Schnyder U, Znoj H, Barth J, et al. The role of illness perception and its association with posttraumatic stress at 3 months following acute myocardial infarction. Front. Psychol 2018; 9(941): 1-10.

4. Morgan K, Villiers-Tuthill A, Barker M, Mc Gee H. The contribution of illness perception to psychological distress in heart failure patients. BMC Psychol 2014; 2(50): 2-9.

5. Carroll L. Passive coping strategies. In: Gellman, M. D., Turner, J. R. (eds). Encyclopedia of Behavioral Medicine. Springer, New York, NY. 2013 [Internet] Available at. https://link.springer.com /referenceworkentry/10.1007\%2F978-1-4419-1005-9_1164.

6. Lafittau M, Radat F, Irachabal S. Headache and transformed migraine with medication overuse: what differences between disability, emotional distress and coping?. Encep 2006; 32(2): 231-7.

7. Frare M, Axia G, Battistella PA. Quality of life, coping strategies, and family routines in children with headache. Head 2002; 42(10): 953-62.

8. Lipton RB, Hamelsky SW, Kolodner KB, Steiner TJ, Stewart WF. Migraine, quality of life, and depression: A population-based case- control study. Neurol 2000; 55(5): 629-35.

9. Neut D, Fily A, Cuvellier JC, Vallee L. The Prevalence of Triggers in Paediatric Migraine: A Questionnaire Study in 102 Children and Adolescents. J Headache Pain 2012; 13(1): 61-65.

10. Broadbent E, Petrie KJ, Main J, Weinman J. The brief illness perception questionnaire. J Psyc Res 2006; 60(6): 631-37.

11. Khan MN, Akhter MS, Ayub M, Alam S, Laghari NU. Translation and validation of quality of life scale, the brief version. J Coll Phys Surg Pak 2003; 13(2): 98-00.
12. Akhtar M. Coping strategies and its relationship with stress and time demands among university students (Unpublished M.phil Thesis). National Institute of Psychology, Quaid-e-Azam University, Islamabad. 2005 [Internet] Available at. https://scholar. google.com/scholar?hl=en\&as_sdt $=0 \% 2 \mathrm{C} 5 \& \mathrm{q}=$ Coping + strategies+and+its+relationship+with+stress+and+time+deman ds+among+university+students $+\% 28$ Unpublished + M.phil+Thes is \% 29.+National+Institute+of+Psychology $\% 2 C+$ Quaid-e+Azam+University\%2C+Islamabad.+2005.\& btnG.

13. Asnani MR, Barton- Gooden A, Grindley M, Knight-Madden J. Disease knowledge, illness perceptions, and quality of life in adolescents with sickle cell disease: Is there a link. Glob Pediatr Health 2017; 4(1): 1-10.

14. Catunda C, Seidl EMF, Lemetayer F. Quality of life of people living with HIV/AIDS: Effects of illness perception and coping strategies. Psychol Theory Res 2017; 32(especial): 1-7.

15. Holubova M, Prasko J, Ociskova M, Grambal A, Slepecky M, Marackova M. Quality of life and coping strategies of out-patients with a depressive disorder in maintenance therapy - a crosssectional study. Neuropsychiatr Dis Treat 2017; 14(1): 73-82.

16. Zang M, Hong L, Zang T, Lin Y, Zheng S, Zhou X, Fan R, et al. Illness perceptions and stress: mediators between disease severity and psychological well-being and quality of life among patients with Crohn's disease. Patient Prefer Adherence 2016; 10(1): 2387-96.

17. Vazquez-Colon CA. Coping skills, social support, and quality of life among puertorican women undergoing drug and/or alcohol treatment. Western Washington University Masters Thesis Collection 2016 [Internet] Available at: https://cedar.wwu. edu/cgi/ viewcontent.cgi?referer=https:/ / scholar.google.com/\& httpsredir $=1 \&$ article $=1544 \&$ context $=$ wwuet.

18. Tiemensma J, Gaab E, Voorhaar M, Asijee J, Kaptein AA. Illness perceptions and coping determine quality of life in COPD patients. Int J Chron Obstruct Pulmon Dis 2016; 143(11): 1117-54.

19. Broadbent E, Wilkes C, Koschwanez H, Weinman J, Norton S. A systematic review and meta-analysis of the brief illness perception questionnaire. Psychol Health 2015; 30(11): 1361-85.

20. Dempster M, Howell D, McCorry NK. Illness perceptions and coping in physical health conditions: A meta-analysis. J Psychosom Res 2015; 79(6): 506-13. 